\title{
Revisión Sistemática: La movilización precoz es mejor que el reposo en cama para condiciones médicas y quirúrgicas
}

Bed rest: a potentially harmful treatment needing more careful evaluation. Allen C, Glasziou P, Del Mar C. Lancet. 1999;354:1229-33

\section{Objetivo}

Evaluar la eficacia o efectos adversos del reposo en cama (versus movilización temprana) en pacientes con cualquier condición clínica o luego de procedimientos quirúrgicos.

\section{Fuente de datos}

Se identificaron ensayos clínicos controlados y aleatorizados. La búsqueda bibliográfica abarcó MEDLINE y en la Cochrane Library (desde 1966 hasta junio de 1998). Los autores también buscaron artículos relevantes, bibliografías personales y artículos de revisión.

\section{Selección de estudios}

Los estudios fueron seleccionados si a los participantes se les recomendó reposo en cama para un número de condiciones diferentes y fueron estudiados en el mismo ámbito (hospital u hogar). Los participantes recibieron los mismos tratamientos (incluyendo drogas, cirugía o terapia física), excepto por la cantidad de reposo en cama prescripto.

\section{Extracción de datos}

Los datos fueron extraídos sobre los siguientes procedimientos: punción lumbar, anestesia espinal, radiculografía, cateterismo cardíaco, injerto cutáneo por quemaduras, biopsia hepática, fijación de fractura femoral, cirugía de lesiones por decúbito e íleo post cirugía gástrica; y las siguientes condiciones clínicas: dolor lumbar agudo, trabajo de parto espontáneo, hipertensión gravídica con proteinuria, amenaza temprana de aborto, infarto de miocardio no complicado, tuberculosis pulmonar, artritis reumatoidea y hepatitis infecciosa aguda.

\section{Resultados}

La revisión incluyó 39 estudios con 5777 pacientes, abarcando 15 condiciones. Se presentaron los Odds Ratios individuales y no una medida sumaria debido a la variabilidad de los estudios.

En 24 estudios que investigaron reposo en cama luego de un procedimiento médico, 7 puntos finales fueron levemente mejores con el reposo en cama (pero ninguno estadísticamente significativo), 26 puntos finales fueron peores con el reposo en cama (9 de los cuales mostraron significancia estadística). No se demostró beneficio significativo en 10 estudios que examinaron la frecuencia de cefalea luego de punción lumbar con distintos protocolos de reposo en cama.

Nueve estudios evaluaron el efecto de diferentes períodos de reposo en cama luego de cateterismo cardíaco, con períodos de deambulación precoz entre 2 a 6 hs. Los resultados sugirieron que 2.5 hs de reposo es suficiente luego del cateterismo con catéteres de $5 \mathrm{~F}$ o $6 \mathrm{~F}$, y 4 hs es suficiente luego de cateterismo con catéteres de $7 \mathrm{~F}$. En 15 estudios que investigaron reposo en cama como tratamiento primario, 6 puntos finales fueron levemente superiores con el reposo en cama, pero ninguno fue significativo, 25 puntos finales mostraron resultados peores con el reposo ( 9 de los cuales alcanzaron significancia estadística).

Hubo 3 estudios sobre el uso de reposo en cama en patología obstétrica: uno reportó en forma estadísticamente significativa peores resultados con el reposo en cama en la primera etapa del trabajo de parto.

\section{Conclusión}

Los autores concluyen que no hay evidencia para recomendar reposo en cama como tratamiento primario de condiciones médicas o luego de procedimientos médicos o quirúrgicos. Más aún, en algunas circunstancias el reposo podría ser perjudicial.

\section{Comentario}

Durante varios años el reposo en cama fue una indicación frecuente para distintas condiciones médicas y quirúrgicas, aceptado sin un claro sentido crítico. Sin embargo, en los últimos años, junto a las mayores pruebas que se le pide a una intervención para indicarla, existe una tendencia "revisionista" en lo que respecta a la utilidad del reposo..$^{1-5}$ En lo que respecta a la presente revisión sistemática, los estudios revisados son tan variados que es difícil extraer conclusiones firmes. A su vez, esta revisión presenta algunas debilidades: los estudios incluidos varían enormemente en su fecha de publicación, cambiando también las recomendaciones médicas a lo largo del tiempo; los autores no pudieron realizar análisis sumario de los datos; no reportaron quién o cómo se realizó la selección de los estudios o quién realizó la extracción de los datos. Tampoco incluye datos de la validez de los estudios incluidos. Estas limitaciones metodológicas llevan a los autores a concluir que no deberían asumir ninguna eficacia del reposo en cama y que se necesitan más estudios para establecer cuándo el reposo en cama es realmente un tratamiento perjudicial.
Sin embargo, la idea de que el reposo en cama puede tener efectos adversos es correcta. El reposo prolongado en cama puede contribuir al desarrollo de neumonía, trombosis venosa profunda, lesiones cutáneas por decúbito, además de disminuir la masa ósea y la fuerza muscular.

Hay evidencia suficiente como para afirmar que el reposo en cama, o el reposo prolongado en cama, es perjudicial para condiciones tales como dolor lumbar agudo e infarto de miocardio y procedimientos como cirugía de cadera.

Conclusiones del Comentador: En situaciones donde aún la evidencia es equívoca, debemos evaluar cuidadosamente en cada situación, teniendo en cuenta que la movilización precoz es probablemente mejor que el reposo en cama para la mayoría de las intervenciones evaluadas. En el caso puntual de la lumbalgia, esto hoy en día es claro. ${ }^{1,3,5}$

\section{Dr. Germán de la Llave [ Médico Clínico. Coordinador Cuidados Domiciliarios Medicus ]}

\section{Referencias}

1. Hagen KB, Hilde G, Jamtvedt G, Winnem MF. The cochrane review of advice to stay active as a single treatment for low back pain and sciatica. Spine. 2002 Aug 15;27(16):1736-41

2. McArthur J. Review: Ionger bed rest does not prevent more postpuncture headaches than immediate mobilisation or short bed rest. Evid Based Nurs. 2002 Jul;5(3):87.

3. Quittan M. Management of back pain. Disabil Rehabil. 2002 May 20;24(8):423-34. Review.

4. Thoennissen J, Herkner H, Lang W, Domanovits $\mathrm{H}$, Laggner AN, Mullner M. Does bed rest after cervical or lumbar puncture prevent headache? A systematic review and meta-analysis. CMAJ. 2001 Nov 13;165(10):1311-6. Review.

5. French L. Bed rest ineffective as therapy. J Fam Pract. 2000 Jan;49(1):9-10 